\title{
EFFECT OF FIBRE ASPECT RATIO AND FIBRE VOLUME FRACTION ON THE EFFECTIVE FRACTURE ENERGY OF ULTRA-HIGH-PERFORMANCE FIBRE-REINFORCED CONCRETE
}

\author{
Radoslav Sovják*, Petr Máca, Tomáš Imlauf \\ Experimental Centre, Faculty of Civil Engineering, Czech Technical University in Prague, Thákurova 7, 16629 \\ Prague 6, Czech Republic \\ * corresponding author: sovjak@fsv.cvut.cz
}

\begin{abstract}
This paper investigates the effective fracture energy of UHPFRC with various fibre volume fractions and various fibre aspect ratios. We have concluded that the effective fracture energy is dependent on both the fibre volume fraction and the fibre aspect ratio. In addition, we have found that both dependencies follow a linear trend.
\end{abstract}

KEYWORDS: effective fracture energy; UHPFRC; straight steel micro-fibres; fibre volume fraction; fibre aspect ratio; simplified predictive model.

\section{INTRODUCTION}

Ultra-high-performance fibre-reinforced concrete (UHPFRC) is an advanced cementitious composite with enhanced mechanical and durability properties that outperforms conventionally used concretes in many ways. Such a material with certain properties and specifications is well suited for energy absorption facade panels and key elements of building structures that may be exposed to impacts [1-3] or blast loads [47. In the event of such a disaster, a large deformation of the structural member is expected, while the exposed member is required to continue to possess some residual capacity to carry the load. It can be stated that the resistance of civil infrastructure is strongly related to the energy absorption capacity. The capacity of the member to absorb energy can be quantified via the effective fracture energy, which represents the overall energy that a material can absorb per square meter. Many researchers have demonstrated the considerably higher energy absorption capacity of UHPFRC (as indicated by the fracture energy) compared to conventionally used fibre reinforced concretes or normal strength concretes [8-11]. The energy absorption capacity is the main material property that benefits from fibre reinforcement. The effective fracture en$\operatorname{ergy}\left(G_{\mathrm{f}}\right)$ is a key parameter for evaluating the ability of a material to withstand an impact or blast load and also to redistribute the load from the exposed structure to its surrounding parts.

The aim of this study is to investigate the effective fracture energy of UHPFRC with various fibre volume fractions and various aspect ratios. Different behaviour of UHPFRC in terms of $G_{\mathrm{f}}$ can be expected for various fibre volume fractions and for various aspect ratios, as the fibres are the key component of UHPFRC that results in enhanced ductility. The results provided in the present study can serve as valuable information for verifying material mod-

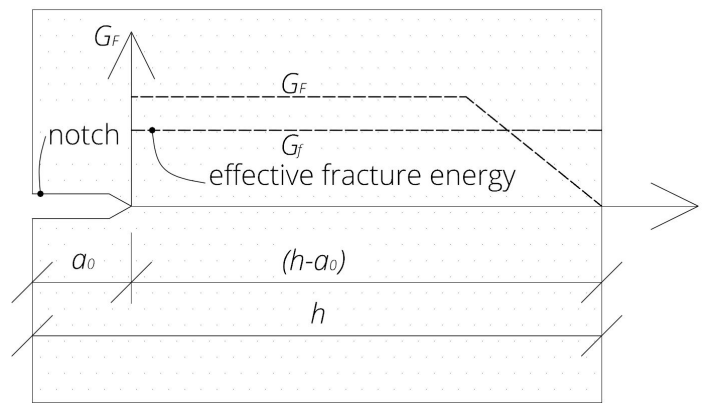

FiguRE 1. Effective fracture energy of a notched specimen.

els, and also for design purposes. This paper also provides an overview of basic mechanical properties of UHPFRC and experimental techniques used. In addition, a brief mixing procedure as well as sample preparation is presented.

\section{EXPERIMENTAL PROGRAM}

The effective fracture energy $\left(G_{\mathrm{f}}\right)$ of a material is defined as the energy required to open a unit crack surface area. The fracture energy is primarily governed by the tensile mechanism of the material, and represents the amount of energy consumed when a crack propagates through a beam. The fracture energy $\left(G_{\mathrm{F}}\right)$ is expressed as the work of external forces acting on the beam related to the actual depth of the crack. The overall work of the external forces related to the final crack depth is considered as the average fracture energy, the so-called effective fracture energy (Fig. 1).

The effective fracture energy $\left(G_{\mathrm{f}}\right)$ was determined in this study on the basis of recommendations presented by the RILEM Technical Committee [12] and also by 


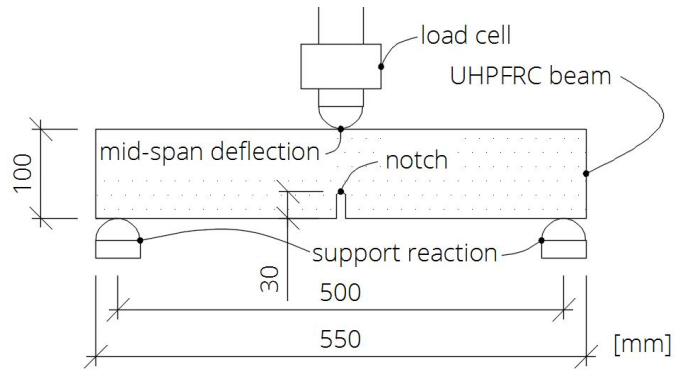

Figure 2. Experimental setup.

other studies $[13,14]$ :

$$
G_{\mathrm{f}}=\frac{W_{\mathrm{f}}+m g u_{\mathrm{u}}}{b\left(h-a_{0}\right)},
$$

where $G_{\mathrm{f}}$ is the effective fracture energy, $W_{\mathrm{f}}$ is the work of external forces (i.e., the area beneath the loaddeflection diagram), and $m g u_{\mathrm{u}}$ is the contribution of the weight of the beam and measurement equipment that is not connected to the loading frame. In detail, $m$ is the mass of the beam and the free experimental equipment, $g$ is gravity acceleration, $u_{\mathrm{u}}$ is the ultimate deflection of the beam, $b$ is the width of the beam, $h$ is the height of the beam, and $a_{0}$ is the height of the notch.

Experiments were performed on beams of $100 \times$ $100 \times 550 \mathrm{~mm}$ in dimensions with a clear span of $500 \mathrm{~mm}$. Similar spans were used in previous studies by Habel and Gauvreau [15] and Sovják et al. [9, for instance. The beams had a notch in their bottom edge which was $30 \mathrm{~mm}$ in height and $5 \mathrm{~mm}$ in width (Fig. 2). Each beam was turned $90^{\circ}$ from the casting surface and then sawed through completely at midspan [16]. The aspect ratio and the fibre volume fraction were set as the main test variables in this study. Three different fibre volume fractions were tested covering 1 , 2 , and $3 \%$ of the fibre volume content. Other studies have shown that the optimal fibre volume fraction for a protective structure or for a defence structure is $2 \%$ by volume [17, 18]. The effect of aspect ratio on $G_{\mathrm{f}}$ was therefore investigated in this study on samples with $2 \%$ of fibres by volume only. The aspect ratios investigated in this study were 50.0, 59.1, 72.2 and 108 : 1 , using fibres of $8.5 \times 0.17 \mathrm{~mm}, 13 \times 0.22 \mathrm{~mm}$, $13 \times 0.18 \mathrm{~mm}$ and $14 \times 0.13 \mathrm{~mm}$, respectively.

Quasi-static loading conditions were simulated by a deformation controlled test with a speed of the cross-head of $0.2 \mathrm{~mm} / \mathrm{min}$. This speed corresponded to a strain rate of $5.6 \cdot 10^{-6} \mathrm{~s}^{-1}$, which is considered as the quasi-static strain rate [19, 20]. During the experimental program, the force acting on the beam and the deflection measured by two LVDT (linear variable differential transformer) sensors were recorded with $5 \mathrm{~Hz}$ frequency. Steel yokes were implemented in the experimental setup as mounts for the LVDT sensors, in order to subtract the settlement of the supports from the measured deflections [21].
The compressive strength and secant modulus of elasticity were measured on cylinders with $100 \mathrm{~mm}$ in diameter and of $200 \mathrm{~mm}$ in height. Because the strength of the best available capping material (100 MPa) was significantly lower than the expected measured strengths, the tops of the cylinders were cut off and grinded. Compressive strength was measured on the cylinders by monotonic increments of load with an average speed of $36 \mathrm{MPa} / \mathrm{min}$ up to the level of $70 \%$ of the expected compressive strength. At this point loading was switched to deformation control with a speed of $0.048 \mathrm{~mm} / \mathrm{min}$ for about 20 minutes in order to measure peak and post peak behaviour. The modulus of elasticity was measured using two strain gauges with a $50 \mathrm{~mm}$ base, attached to the sides of the cylinder specimen. A hydraulic loading machine was used and the loading procedure was stress controlled. As a first step the specimens were loaded to $1 / 3$ of expected maximal compressive strength in this case $50 \mathrm{MPa}$ - for 60 seconds. Afterwards the specimens were unloaded to $5 \mathrm{MPa}$. This procedure was repeated three times. The secant modulus of elasticity was calculated from the third unloading cycle.

The modulus of rupture in a three-point bending configuration was measured on prisms with dimensions of $400 \times 100 \times 100 \mathrm{~mm}$ with a clear span of $300 \mathrm{~mm}$. The loading speed was $0.1 \mathrm{~mm} / \mathrm{min}$. A direct tensile test was carried out on dog-bone shaped specimens without a notch. The length of the specimens was $330 \mathrm{~mm}$ and the cross-section of the narrowed part was $30 \times$ $30 \mathrm{~mm}$ with a length of $80 \mathrm{~mm}$. The specimens were mounted into specially developed grips and the loading speed was $0.1 \mathrm{~mm} / \mathrm{min}$. Splitting tensile strength was measured on cylinders with $100 \mathrm{~mm}$ in diameter and with a length of $100 \mathrm{~mm}$. The splitting tensile test was stress controlled and the loading speed was $3 \mathrm{MPa} / \mathrm{min}$.

\section{MATERIAL}

The UHPFRC tested in this study was developed on the basis of components widely available in the Czech Republic. The material design process has been fully described elsewhere [17, 22, 23. High particle packing density is a key property of ultra-high compressive strength of concrete. Therefore the mixture design was based on optimizing the particle packing density of sand $(\mathrm{S})$, silica fume (SF), glass powder (GP) and cement $(\mathrm{C})$. An improvement in particle packing was achieved mainly by changing the matrix composition and proportions and by selecting ranges of particles for sand 24. The first mixture was designed following the proportions of $\mathrm{C}: \mathrm{SF}$ : GP recommended by Wille et al. 25] as $1: 0.25: 0.25$ with a water binder $(w / b)$ ratio of 0.2 . Subsequent changes in the most important parameters such as high-range water reducer (i.e., superplasticizer), water content (W), SF, and GP led to an optimized cementitious matrix (Tab. 1). 


\begin{tabular}{lrrr}
\hline Fibre content & $1 \%$ & $2 \%$ & $3 \%$ \\
\hline Cement CEM I 52,5R & 800 & \\
Silica fume & 200 & \\
Silica powder & 200 & \\
Water & 176 & \\
Superplasticizer & 39 & \\
Fine sand 0.1/0.6 mm & 336 & \\
\hline Fine sand 0.3/0.8 mm & 720 & 640 & 560 \\
Straight steel fibres & 80 & 160 & 240 \\
\hline
\end{tabular}

TABLE 1. Mixture design of the UHPFRC used in this study (values in $\mathrm{kg} / \mathrm{m}^{3}$ ).

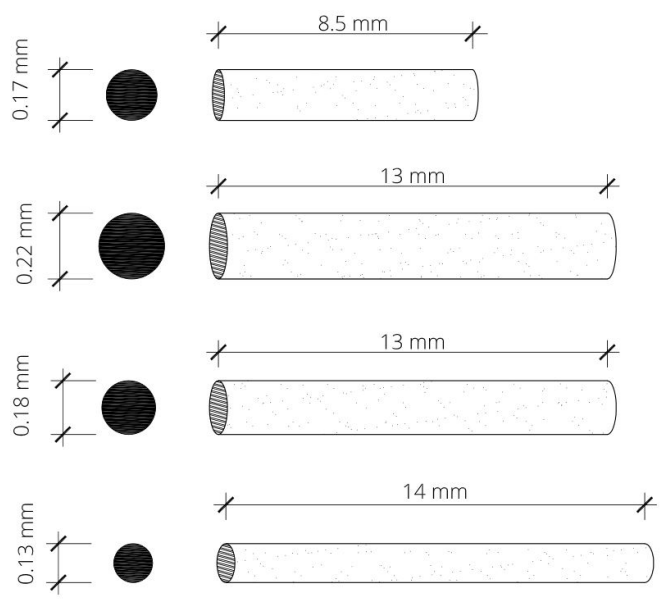

Figure 3. The various micro-fibres used in this study.

The UHPFRC was mixed in conventional mixers, and the beams were cured in water tanks. The mixture contained a high volume of cement and silica fume, and the water-to-binder ratio was 0.18. In this study, the fibre aspect ratio and the fibre volume fraction (i.e., the fibre content) were selected as the main test variables. The high-strength steel micro-fibres used in this study were straight and smooth, with a tensile strength of $2800 \mathrm{MPa}$ (Fig. 3) as specified by the manufacturer. High tensile strength of the fibres was chosen in order to achieve the pull-out failure mode. The pull-out failure mode (Fig. 4a) is a much more energy-consuming mode than the fibre failure mode (Fig. 4p) [26]. Straight fibres also provided a good trade-off between the workability and the mechanical properties of the resulting mixture.

When mixing UHPFRC, it is very important to achieve good workability, particle distribution and packing density. In comparison to normal strength concrete, UHPFRC contains more constituents and finer particles. Several researchers recommend mixing all fine dry particles first, before adding water and superplasticizer [27 29]. They do so because small particles tend to agglomerate and it is easier to break these chunks when the particles are dry. The specific mixing procedure looked as follows: As the first step both types of aggregates and silica fume were mixed a)
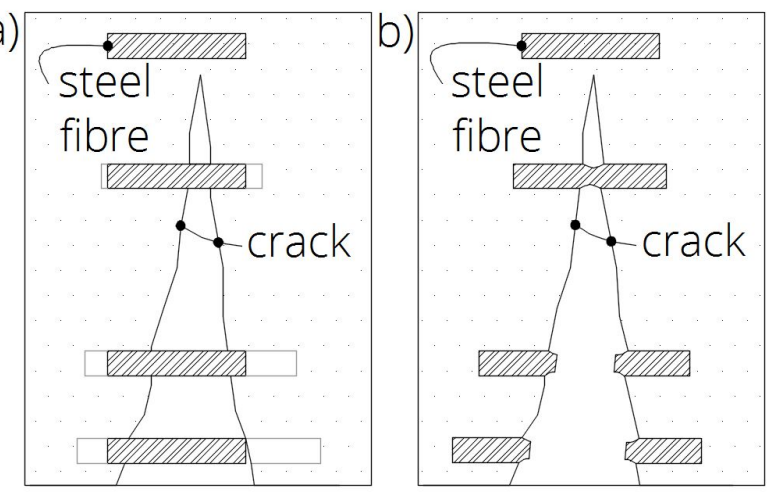

Figure 4. a) Pull-out failure mode. b) Fibre failure mode.

for five minutes. As the second step cement and silica powder were mixed for another five minutes. At the end of the procedure water and superplasticizer were added. The addition of superplasticizer was gradual. The mixture became fully workable after another 5 minutes. Fibres were added gradually into the flowable mixture, to avoid chunk formation, during the last 5 minutes of mixing. The shear action of the fibres helped to destroy any remaining agglomerates in the mixture, thus improving workability. The total mixing time was 20 minutes. A food-type mixer with a capacity of 251 was used to prepare the samples.

The placement of the fresh UHPFRC mixture in the moulds caused the fibres to be aligned along the length of the beam [30]. UHPFRC had flowable and self-consolidating characteristics, so beams made of UHPFRC were fabricated by placing concrete at a certain point of the mould and allowing it to flow [16, 31. This led to fibre alignment in the direction of the tensile stress, because when filling the fresh UHPFRC into formwork, the fibres in the zones near the surface are predominantly oriented parallel to the formwork walls (the so-called wall effect) 32. No other technique was used to align the fibres. All beams were tested after 28 days from casting in order to avoid the effect of ageing, which may also influence the results 33 .

UHPFRC is usually cured using pressure or elevated temperature. This helps to enhance its properties by accelerating the hydration reaction of the binder. However, this is not only energy-expensive but it also limits the usage of UHPFRC to precast elements production. Therefore, the UHPFRC investigated in this study is a self-consolidating concrete with fast strength development which does not require heat curing or special mixing techniques.

As shown in Tab. 2 and Tab. 3 the compressive strength measured on cylinders of $200 \mathrm{~mm}$ in height and $100 \mathrm{~mm}$ in diameter was around $150 \mathrm{MPa}$. The compressive strength did not vary, either with an increasing fibre content or with various fibre aspect ratios. However, the uniaxial tensile strength, the splitting tensile strength (Tab. 2) and the modulus of 


\begin{tabular}{lccc}
\hline Fibre content & $1 \%$ & $2 \%$ & $3 \%$ \\
Fibre geometry & \multicolumn{3}{c}{$13 \times 0.22 \mathrm{~mm}$} \\
\hline Cylinder compressive strength (MPa) & 150 & 152 & 150 \\
Tensile strength (MPa) & 7.80 & 9.90 & 11.7 \\
Modulus of rupture (MPa) & 15.8 & 25.6 & 33.8 \\
Splitting tensile strength (MPa) & 14.9 & 20.5 & 26.6 \\
Modulus of elasticity (GPa) & 45.1 & 56.3 & 51.5 \\
\hline
\end{tabular}

TABLE 2. Mechanical properties of the UHPFRC used in this study.

\begin{tabular}{|c|c|c|c|c|c|c|c|c|}
\hline \multirow{3}{*}{$\begin{array}{c}\text { Fibre } \\
\text { content }\end{array}$} & \multicolumn{8}{|c|}{ Fibre geometry (aspect ratio) } \\
\hline & \multicolumn{2}{|c|}{$\begin{array}{c}8.5 \times 0.17 \mathrm{~mm} \\
\quad(50.0: 1)\end{array}$} & \multicolumn{2}{|c|}{$\begin{array}{c}13 \times 0.22 \mathrm{~mm} \\
(59.1: 1)\end{array}$} & \multicolumn{2}{|c|}{$\begin{array}{l}13 \times 0.18 \mathrm{~mm} \\
\quad(72.2: 1)\end{array}$} & \multicolumn{2}{|c|}{$\begin{array}{l}14 \times 0.13 \mathrm{~mm} \\
\quad(108: 1)\end{array}$} \\
\hline & CCS & MOR & CCS & MOR & CCS & MOR & CCS & MOR \\
\hline $1 \%$ & - & - & $150(2.4)$ & $15.8(2.5)$ & - & - & - & - \\
\hline $2 \%$ & $144(6.1)$ & $21.0(1.6)$ & $152(7.4)$ & $25.6(1.5)$ & $147(5.2)$ & 27.0 & $148(3.3)$ & $36.5(2.5)$ \\
\hline $3 \%$ & - & - & $150(6.5)$ & $33.8(1.4)$ & - & - & - & - \\
\hline
\end{tabular}

TABLE 3. Cylinder compressive strength (CCS) and modulus of rupture (MOR) of the UHPFRC used in this study (values in $\mathrm{MPa}$ ). The value in parentheses gives the standard deviation from the tested specimens.

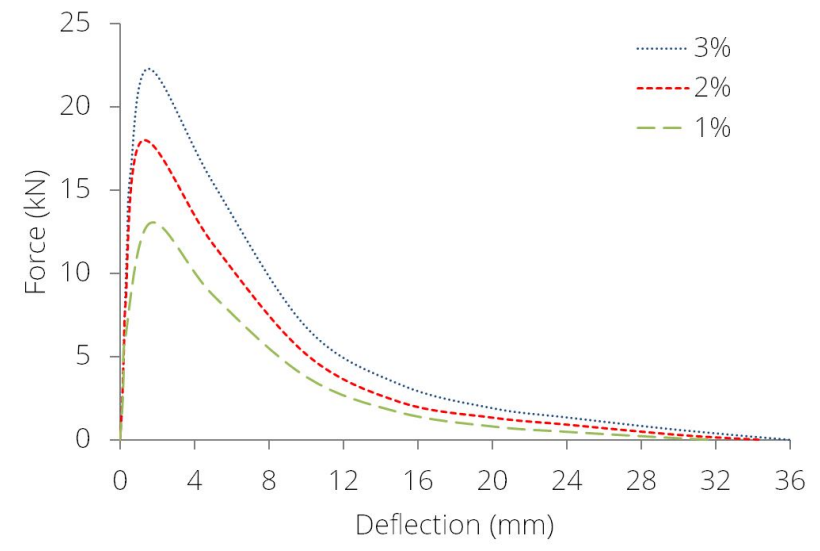

FiguRE 5. Load-deflection diagrams for UHPFRC beams with various fibre contents.

rupture (Tab. 3 showed a linear dependence on the actual fibre content or aspect ratio. The maximum tensile strength was determined to be $11.7 \mathrm{MPa}$ when the fibre content was $3 \%$ by volume [10].

\section{Results AND Discussion}

Load-deflection (L-D) diagrams were plotted for all beams including various fibre volume fractions (Fig. 5) and various aspect ratios (Fig. 6). Six beams were tested for all fibre contents and for all fibre aspect ratios, making a total of 36 tested beams.

The experimental results obtained in this study showed that an increase both in the aspect ratio of the fibres and in the fibre volume fraction resulted in an increase in the effective fracture energy (Tab. 4). In addition, both results appear to follow a linear trend (Fig. 7, Fig. 8).

Data obtained by other researchers dealing with

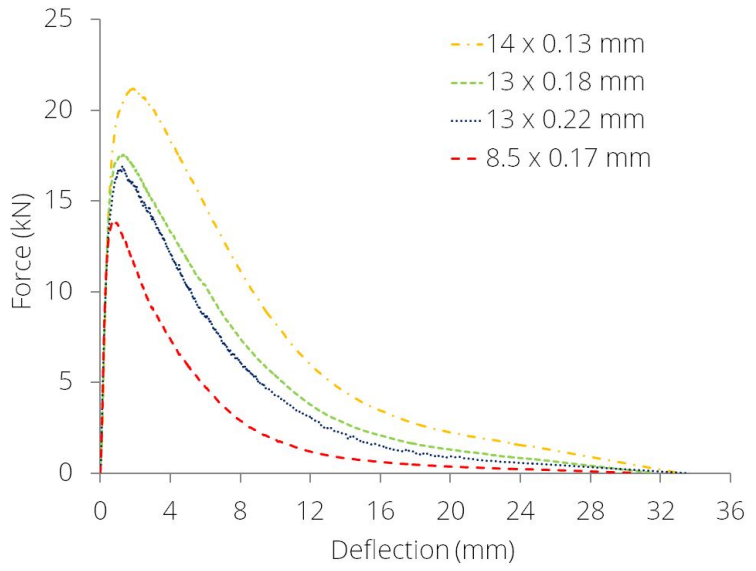

FiguRE 6. Load-deflection diagrams for UHPFRC beams with various aspect ratios.

UHPFRC with straight steel micro-fibres subjected to flexure using notched specimen were examined in order to verify the results derived from this study. Kang et al. 34 tested UHPFRC using a notched 3-point bending test, where the fibre volume fraction varied from 1 to $5 \%$. The UHPFRC used in their study was mixed using a w/b ratio of 0.2 and steel fibres with an aspect ratio of $65(13 \times 0.2 \mathrm{~mm})$. The tensile strength of the fibres was specified to be $2500 \mathrm{MPa}$. The beams were $400 \mathrm{~mm}$ in length (300 $\mathrm{mm}$ clear span) with a notch $30 \mathrm{~mm}$ in height. The effective fracture energy derived from their study increased approximately linearly with an increasing fibre volume fraction until $5 \%$. A linear increase in $G_{\mathrm{f}}$ was also observed in the work conducted by Yoo et al. 35. Yoo et al. tested UHPFRC up to $4 \%$ of the fibre volume fraction, and the effective fracture energy values tended to increase as the fibre volume increased (Fig. 9). Yoo et al. also 


\begin{tabular}{|c|c|c|c|c|}
\hline \multirow{2}{*}{$\begin{array}{c}\text { Fibre } \\
\text { content }\end{array}$} & \multicolumn{4}{|c|}{ Fibre geometry (aspect ratio) } \\
\hline & $\begin{array}{c}8.5 \times 0.17 \mathrm{~mm} \\
\quad(50.0: 1)\end{array}$ & $\begin{array}{c}13 \times 0.22 \mathrm{~mm} \\
\quad(59.1: 1)\end{array}$ & $\begin{array}{c}13 \times 0.18 \mathrm{~mm} \\
\quad(72.2: 1)\end{array}$ & $\begin{array}{c}14 \times 0.13 \mathrm{~mm} \\
\quad(108: 1)\end{array}$ \\
\hline $1 \%$ & - & $12700(2000)$ & - & - \\
\hline $2 \%$ & $10900(1300)$ & $18700(1000)$ & $21000(1700)$ & $32400(4000)$ \\
\hline $3 \%$ & - & $26200(800)$ & - & - \\
\hline
\end{tabular}

TABLE 4. Effective fracture energy $\left(G_{\mathrm{f}}\right)$ of UHPFRC, in $\mathrm{J} / \mathrm{m}^{2}$. The value in parentheses gives the standard deviation from the tested beams.

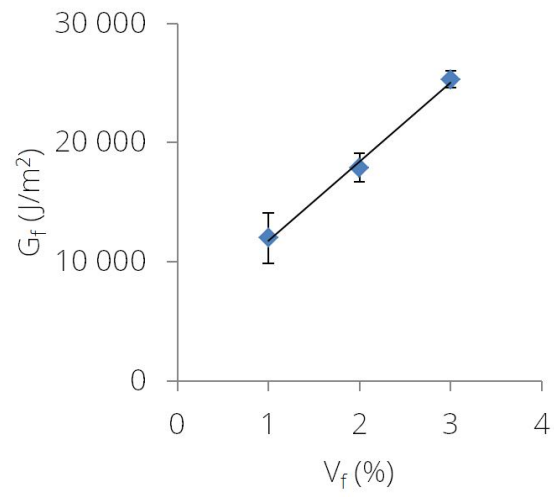

Figure 7. Development of the effective fracture energy in the framework of various fibre volume fractions.

tested smooth steel fibres with an aspect ratio of 65 $(13 \times 0.2 \mathrm{~mm})$ and with tensile strength of $2500 \mathrm{MPa}$. The beams were $400 \mathrm{~mm}$ in length with a $300 \mathrm{~mm}$-long clear span, and the notch was $10 \mathrm{~mm}$ in height. The average compressive strength of the UHPFRC used by Yoo et al. ranged from $182 \mathrm{MPa}$ to $207 \mathrm{MPa}$.

Fig. 9 shows that $G_{\mathrm{f}}$ increases as $V_{\mathrm{f}}$ increases. In addition, it tends to follow an assumption of linear progression. The forecasting equation for the simplified linear trend model can be expressed as

$$
G_{\mathrm{f}}=G_{\mathrm{f}}^{*}+A \Delta V_{\mathrm{f}},
$$

where $G_{\mathrm{f}}$ is the effective fracture energy, $G_{\mathrm{f}}^{*}$ is the reference sample value of the effective fracture energy (measured), $A$ indicates the size of the increase in $G_{\mathrm{f}}$ when $V_{\mathrm{f}}$ increases by one percent, and $\Delta V_{\mathrm{f}}$ is the change between the reference sample value of $V_{\mathrm{f}}$ and the actual sample value of $V_{\mathrm{f}}$. The domain for the proposed equation is between 1 and $5 \%$ of $V_{\mathrm{f}}$. The experimentally derived constant $A$ was calculated as an average slope, and was determined to be $6500 \mathrm{~J} / \mathrm{m}^{2} / \%$.

We have found very little research on UHPFRC with different aspect ratios of the fibres in the framework of high-strength, straight and smooth steel micro-fibres. Yoo et al. 31] tested various aspect ratios of fibres in UHPFRC incorporating $2 \%$ of the fibres by volume. The fibres were $13.0 \mathrm{~mm}, 16.3 \mathrm{~mm}, 19.5 \mathrm{~mm}$ and $30.0 \mathrm{~mm}$ in length and $0.2 \mathrm{~mm}, 0.2 \mathrm{~mm}, 0.2 \mathrm{~mm}$ and $0.3 \mathrm{~mm}$ in diameter, respectively. The UHPFRC used

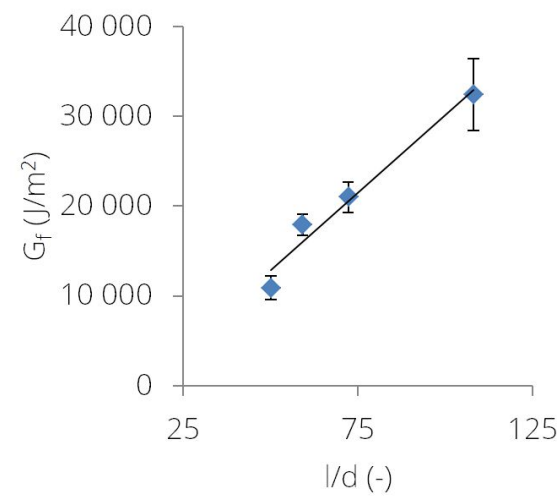

Figure 8. Development of the effective fracture energy in the framework of various aspect ratios.

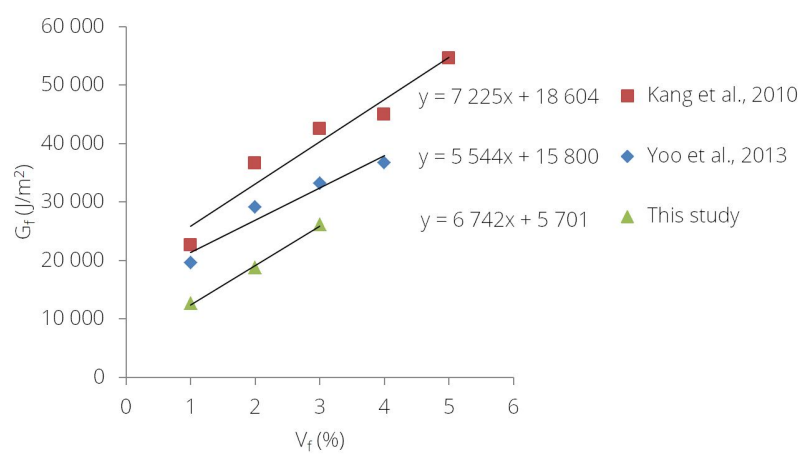

Figure 9. Effect of fibre volume fraction on the effective fracture energy of UHPFRC.

in the study by Yoo et al. was specified by a highest compressive strength of 204.5 MPa for a cylinder with a fibre length of $16.3 \mathrm{~mm}$. Yoo et al. also reported that the compressive strength was somewhat independent from the fibre geometry. The data obtained by Yoo et al. tended to maintain its linear trend throughout the range of aspect ratios used in their study. This trend was found also to be dependent on the reference value of $G_{\mathrm{f}}$ in order to reach the uniform gradient of increments between different studies per change in aspect ratio. It could therefore be noted that both the effective fracture energy and the aspect ratio increase proportionally where the proportionality constant also covers the reference value for the effective fracture energy. The proportionality constant for this trend was specified by the experimental constant $B$ and the reference value of the effective fracture energy $\left(G_{\mathrm{f}}^{*}\right)$. The 


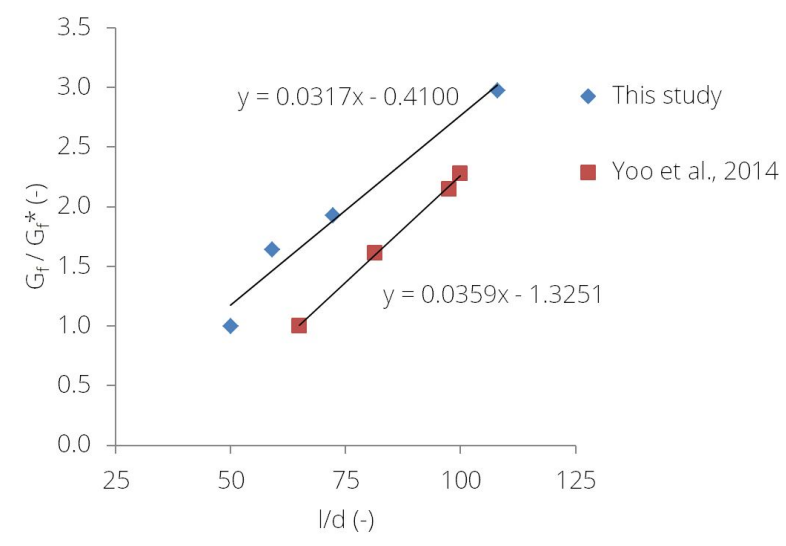

FIGURE 10. Effect of aspect ratio on effective fracture energy of UHPFRC.

experimental constant $B$ was determined to be 0.0338 (Fig. 10). The value of the experimental constant $B$ was calculated as the average slope of the two lines presented in Fig. 10

Fig. 10 shows that $G_{\mathrm{f}}$ increases as $l / d$ increases. The forecasting equation for the simplified linear trend model can therefore be expressed as follows:

$$
G_{\mathrm{f}}=G_{\mathrm{f}}^{*}+B G_{\mathrm{f}}^{*} \Delta \frac{l}{d},
$$

where $G_{\mathrm{f}}$ is the effective fracture energy, $G_{\mathrm{f}}^{*}$ is the reference sample value of the effective fracture energy, $B$ is the experimentally derived constant, and $\Delta \frac{l}{d}$ is the change between the reference sample value of $l / d$ and the actual sample value of $l / d$. The domain for the proposed equation is limited from 50 to $108: 1$ of $l / d$.

Within the framework of the studies discussed here, it is interesting to note that the slope of the linear dependence is not influenced by the matrix composition in the case of various fibre volume fractions. Only the intercept of the line is influenced by various matrix compositions in each study, despite the fact that various matrix compositions lead to different fibre-matrix bond properties, which have a direct influence on the fracture process. On the other hand, the slope of the linear dependence, in the case of various aspect ratios, was found to be influenced by the composition of the matrix. This was reflected by the implementation of the reference value of $G_{f}$ (i.e., the initial value of the line by the lowest $l / d$ in the domain) to the experimental constant B, which reflects the size of the increase in $G_{\mathrm{f}}$ when $l / d$ increases by one unit. Using the reference value of $G_{\mathrm{f}}$ (i.e., $G_{\mathrm{f}}^{*}$ ), a uniform slope of the individual lines was achieved. However, it is important to note that only a limited number of results were found and used in this simplified model, and it is essential to provide more data to upgrade or extend the scope of this trend.

The simplified model for estimating the change in the effective fracture energy due to the change in the aspect ratio and/or in the fibre volume fraction can be established using both dependencies, as presented

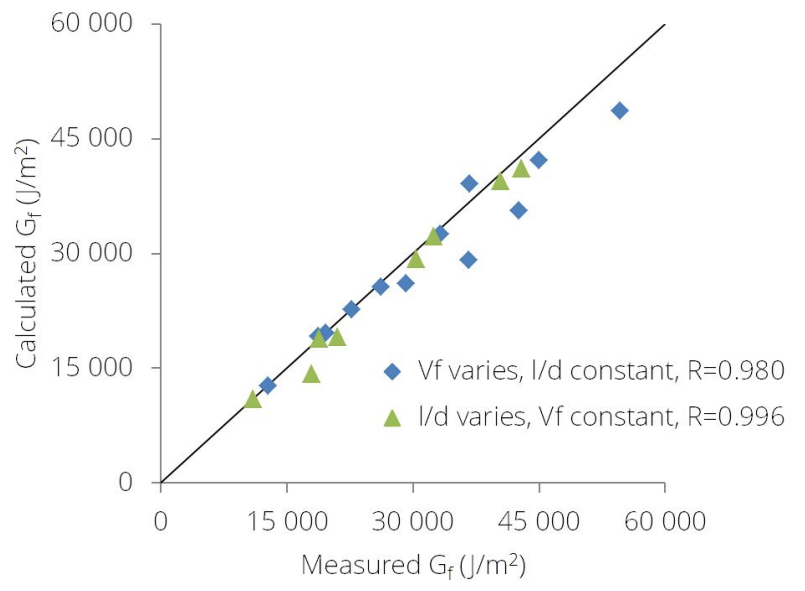

FiguRE 11. Correlation of the results.

in (2) and (3), as follows:

$$
G_{\mathrm{f}}=G_{\mathrm{f}}^{*}+A \Delta V_{\mathrm{f}}+B G_{\mathrm{f}}^{*} \Delta \frac{l}{d},
$$

where $G_{\mathrm{f}}^{*}$ is the reference (measured) value of the effective fracture energy, $A$ and $B$ are experimentally derived constants, $\Delta V_{\mathrm{f}}$ is the change between the reference sample fibre volume fractions and the actual sample fibre volume fractions, and $\Delta \frac{l}{d}$ is the change between the reference sample fibre aspect ratio and the actual sample fibre aspect ratio. The correlation between the results obtained experimentally and the results obtained by the proposed model is shown in Fig. 11.

Fig. 11 shows that the scatter plot follows an approximately linear pattern. The correlation coefficient for all data was calculated to be 0.986 . This value implies that the simplified linear model describes the relationship between $G_{\mathrm{f}}$ and $\Delta V_{\mathrm{f}}$ and between $G_{\mathrm{f}}$ and $\Delta \frac{l}{d}$ with reasonable accuracy. These calculated plots were derived from (4), and they are valid only within the given intervals. We cannot provide any guarantee that the relationship will continue beyond the range for which the data were collected. It can be expected that a further increase in fibre content or aspect ratio beyond these limits will lead the linear relationships to break down. Therefore, an extension of the scope of the current testing by other experimental data is needed.

\section{Conclusions And Further OUTLOOK}

The effective fracture energy was determined on a total of 36 beams, which were tested with various fibre aspect ratios and with various fibre contents. A three-point bending configuration was applied and $\mathrm{L}-\mathrm{D}$ diagrams were examined. A closer examination of the fracture surface revealed fibre pull-out from the matrix, which is more energy-expensive than fibre rupture (Fig. 12).

The fibre volume fraction ranged from 1 to $3 \%$ by volume, and the aspect ratio ranged from 50.0 to 


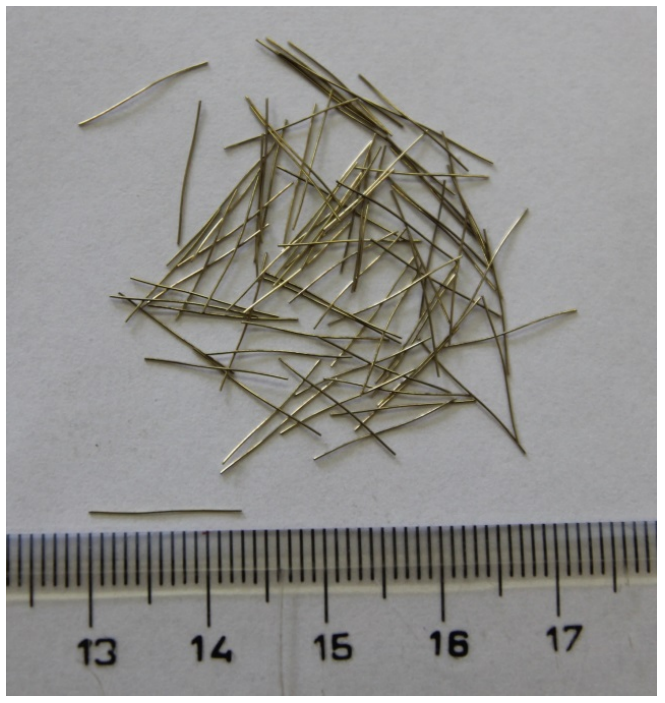

(a)

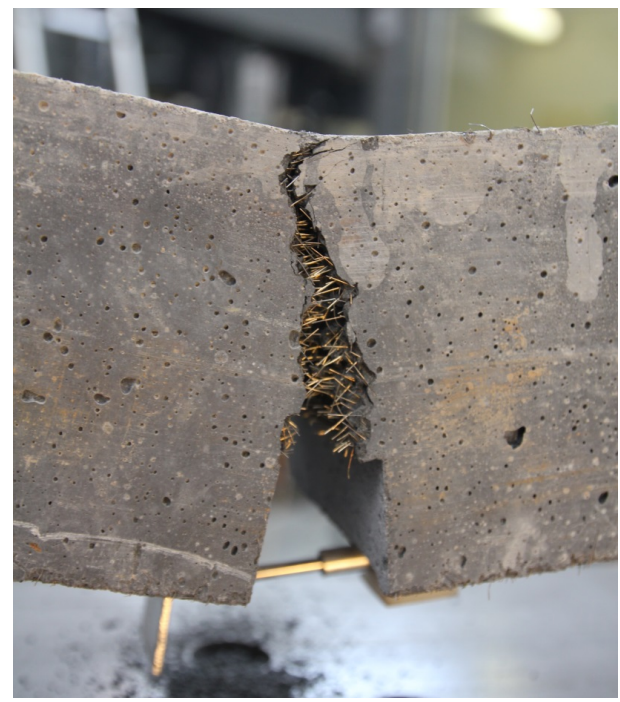

(b)

Figure 12. a) Fibres used in this study. b) Fibre pull-out failure mode.

108 : 1. Other studies [31, 34, 35] were examined and relevant data were obtained to create the simplified model.

The following conclusions can be drawn on the basis of the experimental outcomes derived from our study:

(1.) The effective fracture energy $\left(G_{\mathrm{f}}\right)$ increases as the fibre volume fraction increases. It has been specified that the average increase in $G_{\mathrm{f}}$ per $1 \%$ increase in $V_{\mathrm{f}}$ is approximately $6500 \mathrm{~J} / \mathrm{m}^{2}$.

(2.) The effective fracture energy also increases as the aspect ratio increases. A higher aspect ratio is reflected by a higher absolute number of fibres in the mixture and therefore by a larger surface area. In addition, it was found that the dependence of $G_{\mathrm{f}}$ on the aspect ratio of the fibres tends to follow a linear trend. This has also been confirmed by another study.

(3.) A simplified model was established to calculate the change in the effective fracture energy when the fibre volume fraction or the aspect ratio of the fibres changes. Two experimental constants were established on the basis of the results from this study and other available literature [31, 34, 35].

(4.) An idealization of the linear dependence has been proposed, but the model is valid only within the limits given in Tab. 5 Further extension of the model by other experimental data is needed, especially for higher aspect ratios.

\section{ACKNOWLEDGEMENTS}

The authors gratefully acknowledge the support provided by the Czech Science Foundation under project number GAP 105/12/G059. The authors would like to acknowledge Michaela Kostelecká, from the Klokner Institute, for her assistance with the microscopic investigation of the fibres used in this study. The authors would also like to acknowledge the assistance given by the technical staff

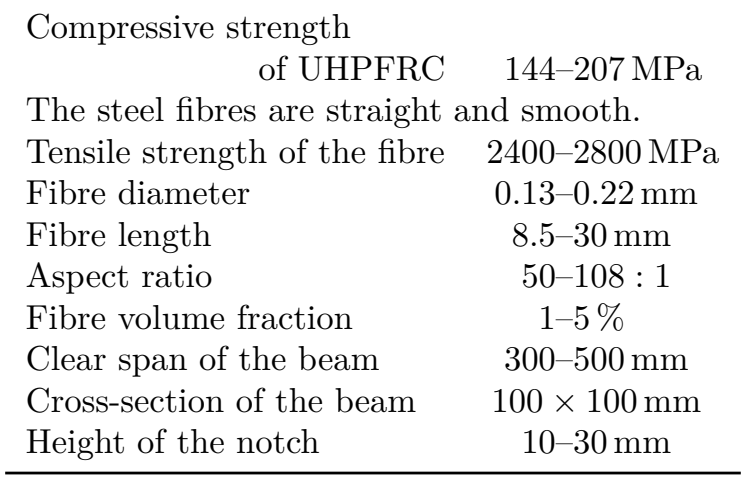

TABLE 5. Limits on the validity of the model.

of the Experimental Centre, Faculty of Civil Engineering, CTU in Prague, and by the students who participated in the project.

\section{REFERENCES}

[1] Millon, O., Riedel, W., et al.: Fiber-reinforced ultra-high performance concrete - a material with potential for protective structures. In: Proceedings of the First International Conference of Protective Structures (Editors: Q. M. Li et al.). Manchester: Manchester, 2010, p. no.-013.

[2] Máca, P., Sovják, R., et al.: Mix design of UHPFRC and its response to projectile impact. International Journal of Impact Engineering, 63, 2014, p. 158-163. DOI:10.1016/j.ijimpeng.2013.08.003

[3] Sovják, R., Vavřiník, T., et al.: Experimental investigation of ultra-high performance fiber reinforced concrete slabs subjected to deformable projectile impact. In: Procedia Engineering. 2013, p. 120-125. DOI:10.1016/j.proeng.2013.09.021

[4] Lai, J., Guo, X., et al.: Repeated penetration and different depth explosion of ultra-high performance concrete. International Journal of Impact Engineering, 84, 2015, p. 1-12. DOI:10.1016/j.ijimpeng.2015.05.006 
[5] Li, J., Wu, C., et al.: Investigation of ultra-high performance concrete slab and normal strength concrete slab under contact explosion. Engineering Structures, 102, 2015, p. 395-408. DOI:10.1016/j.engstruct.2015.08.032

[6] Nicolaides, D., Kanellopoulos, A., et al.: Experimental field investigation of impact and blast load resistance of Ultra High Performance Fibre Reinforced Cementitious Composites (UHPFRCCs). Construction and Building Materials, 95, 2015, p. 566-574. DOI:10.1016/j.conbuildmat.2015.07.141

[7] Nicolaides, D., Kanellopoulos, A., et al.: Development of a new Ultra High Performance Fibre Reinforced Cementitious Composite (UHPFRCC) for impact and blast protection of structures. Construction and Building Materials, 95, 2015, p. 667-674. DOI:10.1016/j.conbuildmat.2015.07.136

[8] Tran, N.T., Tran, T.K., et al.: Fracture energy of ultra-high-performance fiber-reinforced concrete at high strain rates. Cement and Concrete Research, 79, 2015, p. 169-184. DOI:10.1016/j.cemconres.2015.09.011

[9] Sovják, R., Rašínová, J., et al.: Effective fracture energy of ultra-high-performance fibre-reinforced concrete under increased strain rates. Acta Polytechnica, 54 (5), 2014, p. 358-362. DOI:10.14311/AP.2014.54.0358

[10] Máca, P., Sovják, R., et al.: Experimental Investigation of Mechanical Properties of UHPFRC. Procedia Engineering, 65 (0), 2013, p. 14-19. DOI:10.1016/j.proeng.2013.09.004

[11] Xu, M., Wille, K.: Fracture energy of UHP-FRC under direct tensile loading applied at low strain rates. Composites Part B: Engineering, 80, 2015, p. 116-125. DOI:10.1016/j.compositesb.2015.05.031

[12] Recommendation, R.D.: Determination of the Fracture Energy of Mortar and Concrete by Means of Three-Point Bend Tests on Notched Beames. 1985.

[13] Bažant, Z.P., Kazemi, M.T.: Size dependence of concrete fracture energy determined by RILEM work-offracture method. International Journal of Fracture, 51 (2), 1991, p. 121-138. DOI:10.1007/BF00033974

[14] Hu, X.-Z., Wittmann, F.H.: Fracture energy and fracture process zone. Materials and Structures, 25 (6), 1992, p. 319-326. DOI:10.1007/BF02472590

[15] Habel, K., Gauvreau, P.: Response of ultra-high performance fiber reinforced concrete (UHPFRC) to impact and static loading. Cement and Concrete Composites, 30 (10), 2008, p. 938-946.

[16] Yang, I.H., Joh, C., et al.: Structural behavior of ultra high performance concrete beams subjected to bending. Engineering Structures, 32 (11), 2010, p. 3478-3487. DOI:10.1016/j.engstruct.2010.07.017

[17] Máca, P., Sovják, R., et al.: Mix Design of UHPFRC and its Response to Projectile Impact. International Journal of Impact Engineering, 2013, p. DOI:10.1016/j.ijimpeng.2013.08.003

[18] Sovják, R., Vavřiník, T., et al.: Resistance of slim UHPFRC targets to projectile impact using in-service bullets. International Journal of Impact Engineering, 76, 2015, p. 166-177. DOI:10.1016/j.ijimpeng.2014.10.002
[19] Li, Q.M., Reid, S.R., et al.: Local impact effects of hard missiles on concrete targets. International Journal of Impact Engineering, 32 (1), 2005, p. 224-284. DOI:10.1016/j.ijimpeng.2005.04.005

[20] Beckmann, B., Hummeltenberg, A., et al.: Strain Behaviour of Concrete Slabs under Impact Load. Structural Engineering International, 22 (4), 2012, p. 562-568. DOI:10.2749/101686612X13363929517893

[21] Banthia, N., Trottier, J.-F.: Test Methods for Fexural Toughness Characterization of Fiber Reinforced Concrete: Some Concerns and a Proposition. ACI Materials Journal, 92 (1), 1995, p. DOI:10.14359/1176

[22] Maca, P., Zatloukal, J., et al.: Development of Ultra High Performance Fiber Reinforced Concrete mixture. In: IEEE Symposium on Business, Engineering and Industrial Applications (ISBEIA). IEEE, 2012, p. 861-866. DOI:10.1109/ISBEIA.2012.6423015

[23] Sovják, R., Vogel, F., et al.: Triaxial compressive strength of ultra high performance concrete. Acta Polytechnica, 53 (6), 2013, p. DOI:dx.doi.org/10.14311/AP.2013.53.0901

[24] Máca, P., Sovják, R.: Resistance of ultra high performance fibre reinforced concrete to projectile impact. Structures Under Shock and Impact, 2012, p. 261.

[25] Wille, K., Naaman, A.E., et al.: Ultra-high performance concrete with compressive strength exceeding $150 \mathrm{MPa}(22 \mathrm{ksi})$ : a simpler way. ACI Materials Journal, 108 (1), 2011, p. 46-54. DOI:10.14359/51664215

[26] Bencardino, Rizzuti, et al.: Stress-Strain Behavior of Steel Fiber-Reinforced Concrete in Compression. Journal of Materials in Civil Engineering, 20 (3), 2008, p. 255-263. DOI:10.1061/(ASCE)0899-1561(2008)20:3(255)

[27] Wille, K., El-Tawil, S., et al.: Properties of Strain Hardening Ultra High Performance Fiber Reinforced Concrete (UHP-FRC) under Direct Tensile Loading. Cement and Concrete Composites, 2014, p. DOI:10.1016/j.cemconcomp.2013.12.015

[28] Habel, K., Viviani, M., et al.: Development of the mechanical properties of an Ultra-High Performance Fiber Reinforced Concrete (UHPFRC). Cement and Concrete Research, 36 (7), 2006, p. 1362-1370. DOI:10.1016/j.cemconres.2006.03.009

[29] Habel, K., Charron, J.-P., et al.: Ultra-high performance fibre reinforced concrete mix design in central Canada. Canadian Journal of Civil Engineering, 35 (2), 2008, p. 217-224. DOI:10.1139/L07-114

[30] Fornůsek, J., Tvarog, M.: Influence of Casting Direction on Fracture Energy of Fiber-Reinforced Cement Composites. Key Engineering Materials, 594, 2014, p. 444-448.

DOI:10.4028/www.scientific.net/KEM.594-595.444

[31] Yoo, D.-Y., Kang, S.-T., et al.: Effect of fiber length and placement method on flexural behavior, tensionsoftening curve, and fiber distribution characteristics of UHPFRC. Construction and Building Materials, 64, 2014, p. 67-81. DOI:10.1016/j.conbuildmat.2014.04.007 
[32] Mechtcherine, V., Millon, O., et al.: Mechanical behaviour of strain hardening cement-based composites under impact loading. Cement and Concrete Composites, 33 (1), 2011, p. 1-11. DOI:10.1016/j.cemconcomp.2010.09.018

[33] Holčapek, O., Vogel, F., et al.: Time Progress of Compressive Strength of High Performance Concrete. Applied Mechanics and Materials, 486, 2014, p. 167-172. DOI:10.4028/www.scientific.net/AMM.486.167
[34] Kang, S.-T., Lee, Y., et al.: Tensile fracture properties of an Ultra High Performance Fiber Reinforced Concrete (UHPFRC) with steel fiber. Composite Structures, 92 (1), 2010, p. 61-71. DOI:10.1016/j.compstruct.2009.06.012

[35] Yoo, D.-Y., Lee, J.-H., et al.: Effect of fiber content on mechanical and fracture properties of ultra high performance fiber reinforced cementitious composites. Composite Structures, 106, 2013, p. 742-753. DOI:10.1016/j.compstruct.2013.07.033 